可視化情報 Vol.20 Suppl. No.1（2000 年 7月）

\title{
Evaluation of the Magnetic Field Distributions by Wavelets
}

\author{
Akira EMA, Seiji HAYANO, and Yoshifuru SAITO
}

\begin{abstract}
We are developing a magnetic domain measurement device under a controlled magnetic field distribution. This work is essentially reduced into solving for an ill-posed inverse problem, because available information is a set of desired magnetic field components caused by a current distribution to de determined. When a number of magnetic field components is greater than those of current components, it is possible to apply a conventional least squares mean under the fixed design variables. In order to work out the optimal design parameters, it is essential to use an objective function, which indicates a fitness parameter between the desired and generated magnetic field distributions. In the present paper, we set up a fitness parameter by means of the multi-resolution analysis of a discrete wavelet transform. As a result, the multi-resolution analysis of the discrete wavelet transform becomes an effective tool for the optimal design of the magnetic field control devices.
\end{abstract}

Keywords: magnetic fields, optimal design, discrete wavelets, multi-resolution

\section{1. まえがき}

近年の広汎なデジタル計算機の普及と高性能化に伴い、 多くのデジタル可視化機器が実用化された。コンシュー マユーズを前提とするデジタルカメラ・ビデオのみなら ず、医学では MRI(Magnetic Resonance Imaging)等が 極めて日常的に活用されるに至っている。このようなデ ジタル技術による可視化機器は、単純な CPU(Central Processing Unit)の高性能化や高密度メモリーの開発だ けに拠るものでなく、多くの周辺技術の開発によってな されている。たとえば、MRI 等では、磁界分布を高精度 に制御しなければ高い解像度が実現できない。また、省 スペースを実現するために、これらのデジタル可視化機 器を小型軽量化する社会的必要性も大きく、商品性も小 型・軽量によって評価される。単純なアセンブリィ技術 だけでデジタル可視化機器の小型・軽量化は不可能であ
り、究極は機器の構成材料そのものを開発せざるを得な い。

本論文は、デジタル可視化機器の電源や駆動部分を構 成する変圧器や電動機の小型・軽量化を実現せんとする、 低損失磁性材料開発に必要な測定装置に関する研究の一 端である。磁性材料と非磁性材料の本質的な相違は、材 料そのものが自発磁化を持つか持たないかによる。磁性 材料は自発磁化を有する材料である。自発磁化、すなわ ち、微小な永久磁石を原子レベルで有する金属材料が強 磁性体と呼ばれる。したがって、磁性材料は、非磁化状 態では磁気エネルギーを最小にするために、微小磁石が グルーピングし、磁区構造を形成する。低損失磁性材料 の評価は、外部から加えられる磁界の強度や方向等に対 する磁区構造の変化でなされる。これは、高精度の評価 を行うためには、磁界分布を高精度に制御する必要性が あることを意味する。 
所望の磁界分布を実現する電流分布は、設計パラメー タが与えられれば、最小自乗法で計算可能である。しか し、最適な設計パラメータを決めるには、何らかの評価 関数が必要である。均一磁界分布を前提として、多くの 磁性材料の磁区構造評価はなされる。ドビッシーの 2 次 基底関数を用いた離散值系直交ウェーブレット変換の多 重解像度解析で、最低次であるレベル 1 の分布は平均的 な一様分布を与えることが知られている ${ }^{1,2)}$ 。換言すれ ば、所望の磁界分布はレベル 1 の分布そのものであり、 残りすべての高次レベルの分布は磁界の変化部分を与え る。この性質を利用して、本論文では、均一磁界を生成 する最適設計パラメータを得る評価関数を提案し、その 有効性を報告する。

\section{2. 磁界分布制御装置の最適設計}

\section{1 システム方程式}

変圧器や電動機は、多くの場合、珪素鋼板の積層コア で磁路を構成する。平面状の珪素鋼板の正方形部分を均 一に磁化するため、ここでは、Fig. 1 に示す装置を考え る。上方の正方形部分が所望の磁界分布を実現する範囲 であり、下方の正方面が磁界を生成する電流分布面であ る。所望の磁界分布を表すべクトルを $\mathbf{Y}$ とし、求めるべ

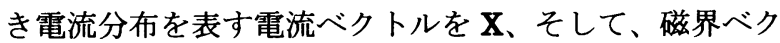
トル $\mathbf{Y}$ と電流ベクトル $\mathbf{X}$ 間の関係を表す $\mathbf{n}$ 行 $\mathbf{m}$ 列のシ ステム行列を $C$ とすれば、解くべきシステム方程式は(1) 式で与えられる ${ }^{3,4)}$ 。

$$
\mathbf{Y}=C \mathbf{X}
$$

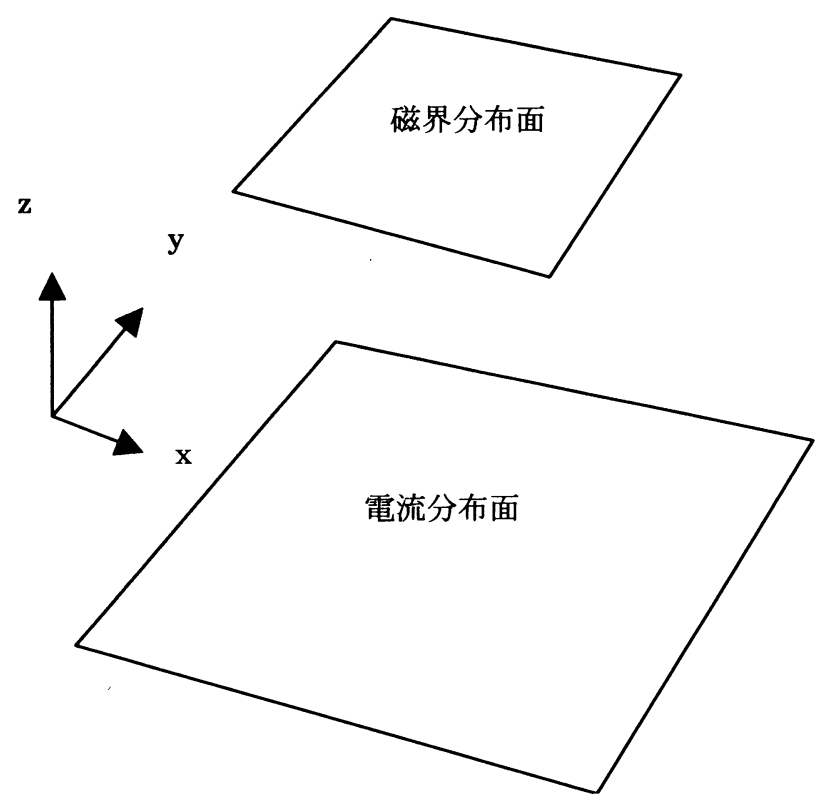

Fig. 1 Schematic diagram of the magnetic field distribution control device

\section{2 最小自乗解}

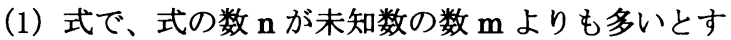
れば、（1）式は（2）式の最小自乗法で近似解を得ること が可能である。条件 $\mathbf{n}>\mathbf{m}$ は、電流が 2 次元平面上に分 布するため、 $\mathbf{x}, \mathbf{y}$ 軸方向の 2 成分のみであるのに対し、 正方形の面上の磁界は $\mathbf{x}, \mathbf{y}, \mathbf{z}$ 方向の 3 成分からなるため、 多くの場合に満足される ${ }^{5,6}$ 。

$$
\mathbf{X}=\left(C^{T} C\right)^{-1} C^{T} \mathbf{Y},
$$

$n>m$

\section{3 最適パラメータの決定}

Fig. 1 のモデルは、磁界分布面を固定とすれば、変更 可能なパラメータは磁界分布面と電流分布面間の距離と 電流分布面の大きさに限定される。磁界分布面が正方形 であるから、電流分布面も正方形とすれば、変更可能な パラメータは、面間の距離 $\mathrm{D}$ と電流分布面の繸または横 の長さ $\mathrm{L}$ となる。これらのパラメータが無限小から無限 大の值を取ることは実際の制作上の観点から不可能であ る。すなわち、 D と L の值は実現可能な範囲に限定され る。面間の距離 D は、大きすぎれば磁界の值が小さくな り、均一分布が実現可能であっても非見実的である。同 様に、電流分布面の大きさ Lも一定の大きさを超えては 非現実的である。

以上の条件を勘案して、10 $\mathrm{cm}^{2}$ の平面に Fig. 2 に示す $\mathrm{z}$ 方向の均一磁界を生成する最適パラメータを計算する。 面間の距離 $\mathrm{D}$ を $5 \mathrm{~mm}$ から $15 \mathrm{~mm}$ 、電流分布面の大きさ Lを $15 \mathrm{~cm}$ から $20 \mathrm{~cm}$ とする。

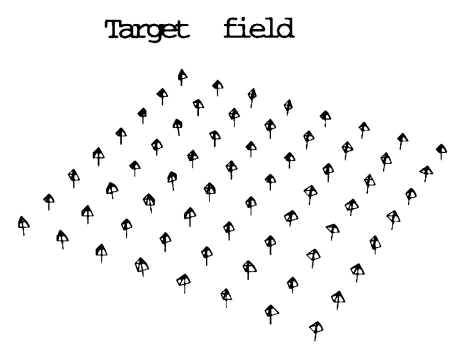

Fig. 2 Target magnetic field distribution

（2）式から得られる解ベクトル $\mathbf{X}$ は、目標磁界ベクト ルYを完全に満足せず、（3）式の誤差ノルムを最小にす る磁界を生成する。

$\varepsilon=|\mathbf{Y}-C \mathbf{X}|$

すなわち、解ベクトルXが与える磁界はFig. 2 の目標磁 界以外の成分を有する。この目標磁界以外の成分で、 $\mathrm{z}$ 方向の磁界は、ドビッシーの 2 次基底関数を用いた多重 解像度解析を用いて分離される。

いま、 $\mathrm{z}$ 方向の磁界分布を $\mathrm{H}_{\mathbf{z}}$ とすれば、ウェーブレッ 卜変換の多重度を $k$ として、 $\mathrm{H}_{\mathrm{z}}$ は（4）式と書ける。 
$\mathbf{H}_{z}=\sum_{i=1}^{k} \mathbf{H}_{i}$

（4）式で、 $i=1$ は最低次のレベルであるから、 $\mathrm{H}_{1}$ は Fig. 2 と同じ均一磁界成分に対応する。逆に、 $i>1$ の成分 はすべて誤差に対応する。従って、評価関数 $f$ を（5）式 で定義する。

$f=\frac{\left|\mathbf{H}_{1}\right|}{\left|\mathbf{H}_{x}\right|+\left|\mathbf{H}_{y}\right|+\sum_{i=2}^{k}\left|\mathbf{H}_{i}\right|}$

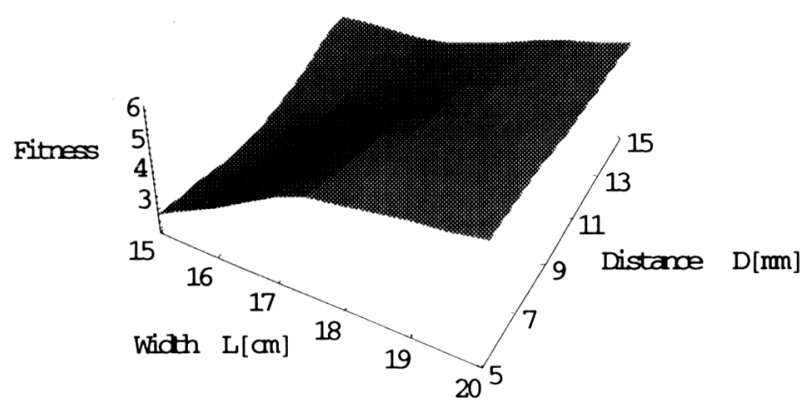

Fig. 3 Variation of the fitness figure $f$
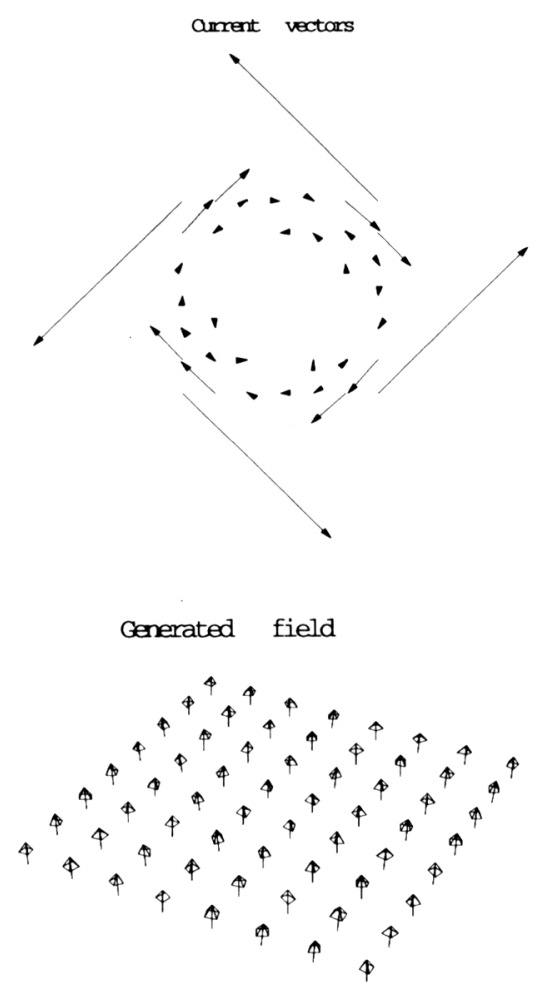

Fig. 4 Current density vectors (upper) and generated magnetic field distribution (lower)
ここで、 $\mathbf{H}_{\mathbf{x}}$ と $\mathbf{H}_{\mathbf{y}}$ はそれぞれ、磁界分布面における磁界 の $\mathbf{x}, \mathbf{y}$ 成分である。

Fig. 3 は評価関数 $f$ の距離 D と長さ L に対する変化を示 す。Fig. 3 から、面間の距離 $\mathrm{D}=5 \mathrm{~mm}$ 、長さ $\mathrm{L}=20 \mathrm{~cm}$ で 評価関数は最大值 6.19 を取ることがわかる。Fig. 4 に、 最適条件 $\mathrm{D}=5 \mathrm{~mm} 、 \mathrm{~L}=20 \mathrm{~cm}$ における電流密度ベクトル の分布と生成される磁界分布を示す。電流密度ベクトル は、外側から内側へ交互に逆方向一流れ、大きさは外側 ほど大きい分布となる。また、磁界はFig. 2 の磁界分布 を概ね再現していることがわかる。しかし、実際はFig. 5 に示すように、 $\mathrm{H}_{\mathbf{z}}$ のレベル 1 は、 $\mathrm{z}$ 方向の均一磁界成分 であるが、 $\mathrm{H}_{\mathrm{z}}$ のレベル 2,3,4には、 $\mathrm{z}$ 方向の不均一磁界 成分が含まれ、 $\mathbf{H}_{\mathbf{x}}, \mathbf{H}_{\mathbf{y}}$ には、 $x, y$ 方向成分の不均一磁 界が含まれる。

\section{3. まとめ}

本論文は磁性材料の磁区観察に必要とされる均一磁界 分布生成装置開発で、ウェーブレット変換の多重解像度 解析を応用した励磁コイルの設計法を提案した。正方形 の面上に均一磁界分布を生成するため、磁界分布面に平 行な正方形の電流分布面を考え、最適な面間の距離およ び電流分布面の大きさを決定するため、ウェーブレット 変換の多重解像度解析を応用した評価関数を提案し、こ の評価関数は最適設計へ極めて有効であることを述べた。 所望の磁界から電流密度べクトルを推定する逆問題は最 小自乗法を用いて解き、近似解を得た。最小自乗法は式 の数が未知数の数よりも多いことを前提とするが、単一 電流分布面で所望の磁界分布を得る場合、良好な近似解 が期待できることが判明した。

\section{参考文献}

1）斎藤兆古 著、Mathematicaによるウェーブレット変換（朝 倉書店、1996 年 9 月）。

2）斎藤兆古 著、ウェーブレット変換の基䃈と応用（朝倉書 店、1998 年 4 月）。

3) H. Takahashi, S. Hayano, Y. Saito, "Visualization of The Currents On The Printed Circuit Boards”, IEEE Visualization 1999, Late Breaking Hot Topics, pp. 37-40, 0ct. 1999.

4) 若林、早野、齋藤、國井、虽井、佐久間、“画像の固有パタ ーンと磁界分布解析への応用”、電気学会マグネチックス研 究会資料、MAG-99-142、15-18（1999 年 11 月）.

5）宮原、早野、齋藤 “淮 3 次元電流分布測定法とその応用”、 電気学会マグネチックス研究会資料、MAG-99-153、35-39 （1999 年 11 月）。

6）関島、早野、齊藤、澤田、堀井、“一般化 SPM 法による二 次元電流分布推定”、電気学会マグネチックス研究会資料、 MAG-99-151、25-29（1999 年 11 月）。 
Hz Level 1
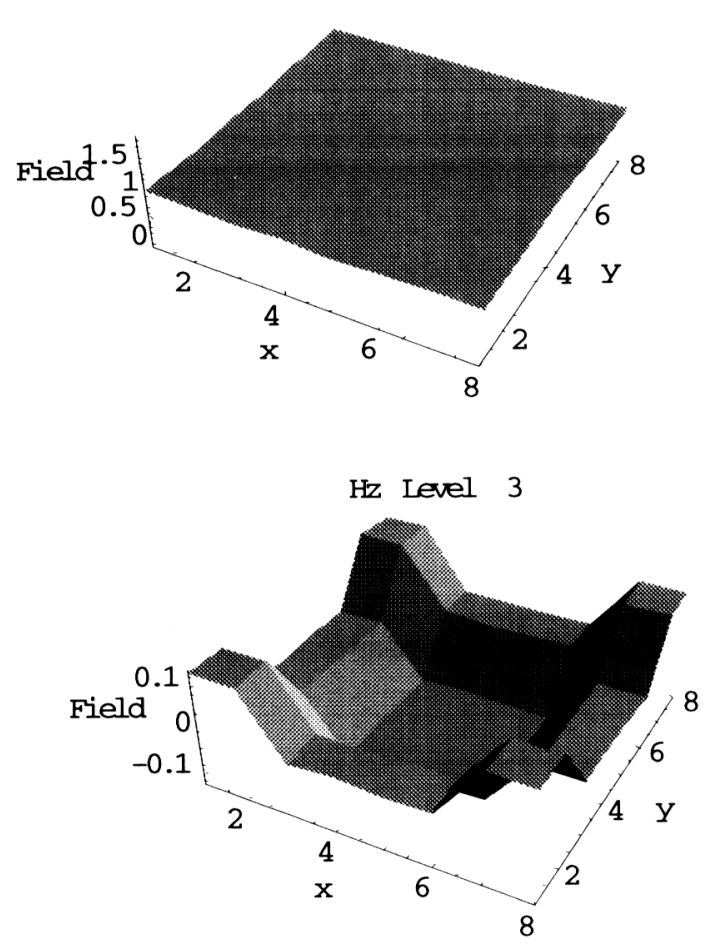

$\mathrm{Hx}$

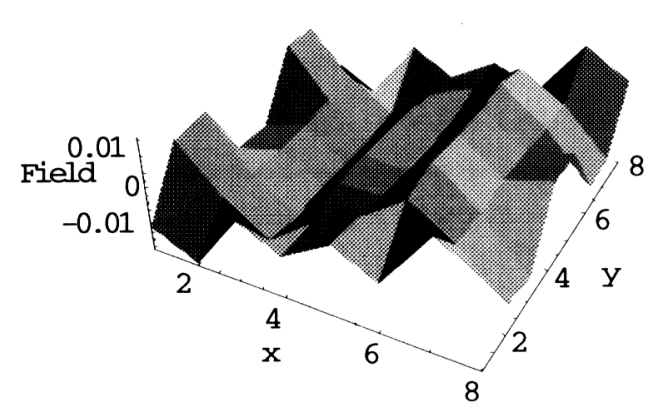

$\mathrm{Hz}$ Level 2

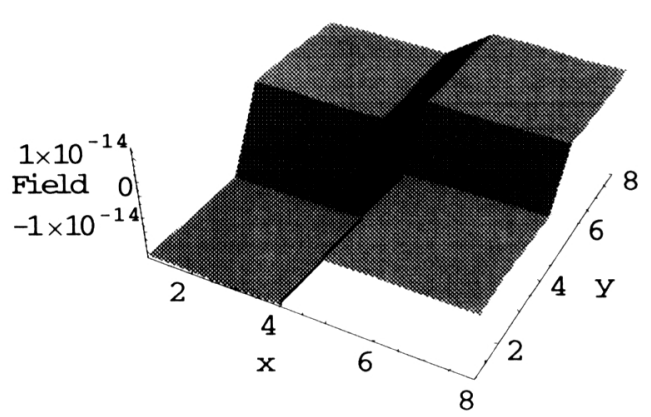

$\mathrm{Hz}$ Level 4

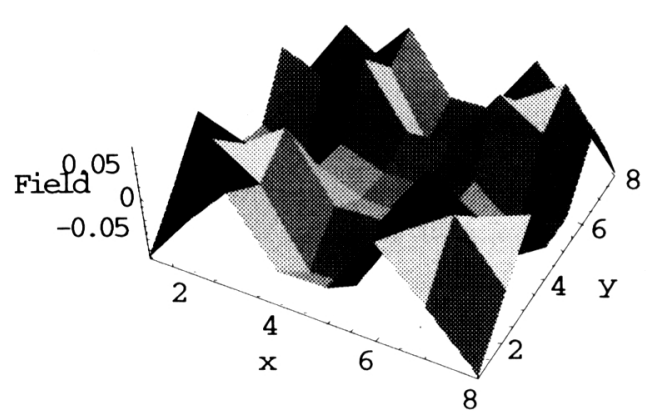

Hy

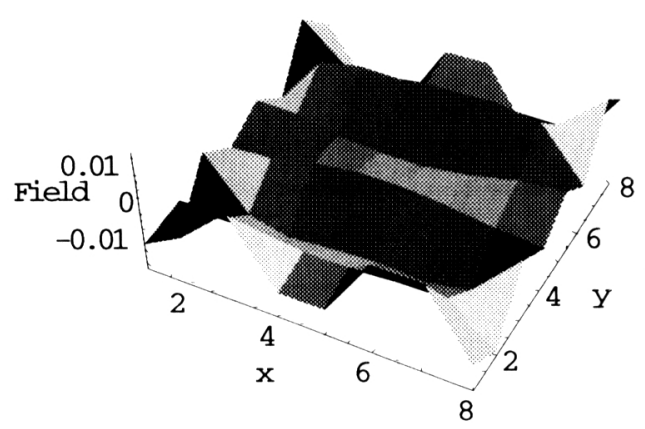

Fig. 5 Magnetic field component distributions 